\title{
Jejunal Neoplasm
}

National Cancer Institute

\section{Source}

National Cancer Institute. Lejunal Neoplasm. NCI Thesaurus. Code C8401.

A benign or malignant neoplasm that affects the wall of the jejunum. Representative examples include adenoma, carcinoma, and lymphoma. 